\title{
Notes on Additional Material Associated with the Type Specimens of Diphuicrinus ohioensis (Echinodermata: Crinoidea) from the Middle Pennsylvanian of Southeastern Ohio
}

JAMES R. THOMKA' and DONALD B. EDDY, Department of Geosciences, University of Akron, Akron, OH, USA.

\begin{abstract}
The cladid crinoid Diphuicrinus ohioensis Burke, 1976, was originally described from shallow marine facies of the Middle Pennsylvanian Putnam Hill Limestone of southeastern Ohio. One of the type localities for this taxon is an abandoned quarry in Vinton County, where a small number of articulated cups used in erection of this species was collected. Prior to formal description of this species, multiple isolated calyx ossicles were collected from this locality, but were not analyzed in detail or included in the description of $D$. ohioensis. The previously unidentified material, described herein, contributes to a more complete record of this taxon. Further, heavily sculptured (nodose) basal and radial plates are nearly ubiquitously encrusted by calcareous tubes, a paleoecological detail not otherwise noted in the description of $D$. ohioensis or the lithofacies from which material was collected. Encrusters, which consist of at least 2 varieties, are present primarily in depressed areas in between raised nodes. This may reflect post-mortem removal via abrading currents but may alternatively represent preferential encrustation of portions of hard bioclasts characterized by larger, smoother, protected surfaces. This study reinforces the value of isolated crinoid ossicles in paleoecology, paleobiology, and paleoenvironmental analysis.
\end{abstract}

Publication Date: July 2018

https://doi.org/10.18061/ojs.v118i2.6189

OHIO J SCI 118(2):25-30

\section{INTRODUCTION}

Isolated crinoid ossicles, reflecting complete postmortem disarticulation of individuals during extended residence within the taphonomically active zone (Lewis 1980), represent one of the most abundant bioclasts in the Paleozoic rock record (Lowenstam 1957; Ausich 1997). Although used to some degree in regional biostratigraphy (e.g., Moore 1938; Fearnhead et al. 2013; Thomka and Brett 2017) and erection of descriptive morphotaxa (e.g., Moore and Jeffords 1968; Donovan 1986), fragmentary crinoid remains are largely under-utilized data sources, particularly in studies of taphonomy, paleoecology, and facies analysis (see Jeffords 1978; Holterhoff 1997; Thomka et al. 2012 and references therein). In addition, isolated crinoid ossicles contribute to greater understanding of the internal morphology and intraspecific variability of taxa that are known from a limited number of specimens. Consequently, careful attention to disarticulated crinoids shows promise for enhancing paleoenvironmental reconstructions, improving understanding of biotic interactions, and increasing records of echinoderm biodiversity and paleobiology.

Nevertheless, articulated or partially articulated material is generally needed to formally describe new crinoid taxa. This can leave associated skeletal material

${ }^{1}$ Address correspondence to James R. Thomka, Department of Geosciences, 114 Crouse Hall, University of Akron, Akron, OH 44325. Email: jthomka@uakron.edu in the form of isolated ossicles collected alongside more complete specimens insufficiently studied or completely ignored in favor of the articulated specimens. This study is an exploration of crinoid material consisting exclusively of loose ossicles representing supplementary material to the articulated cups that served as the sole basis for description of a crinoid species. These specimens provide additional documentation of a taxon with a relatively sparse fossil record and, more importantly, provide paleoecologic and taphonomic information not presented in the initial description.

\section{METHODS AND MATERIALS}

Specimens described here are reposited in the Cleveland Museum of Natural History invertebrate paleontology collection, all under lot number CMNH 16597. A diverse collection of isolated basal plates, radial plates, brachial and anal sac spines, and columnals, collectively representing multiple crinoid taxa, is present. In total, 153 plates are included in this specimen lot, with the distribution of ossicle types given in Fig. 1. Although many plates cannot be reliably identified, 35-including 15 basal plates and 20 radial plates-are herein attributed to the pinnulate cladid crinoid Diphuicrinus obioensis Burke, 1976 (Fig. 1).

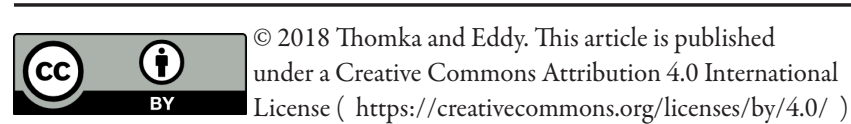




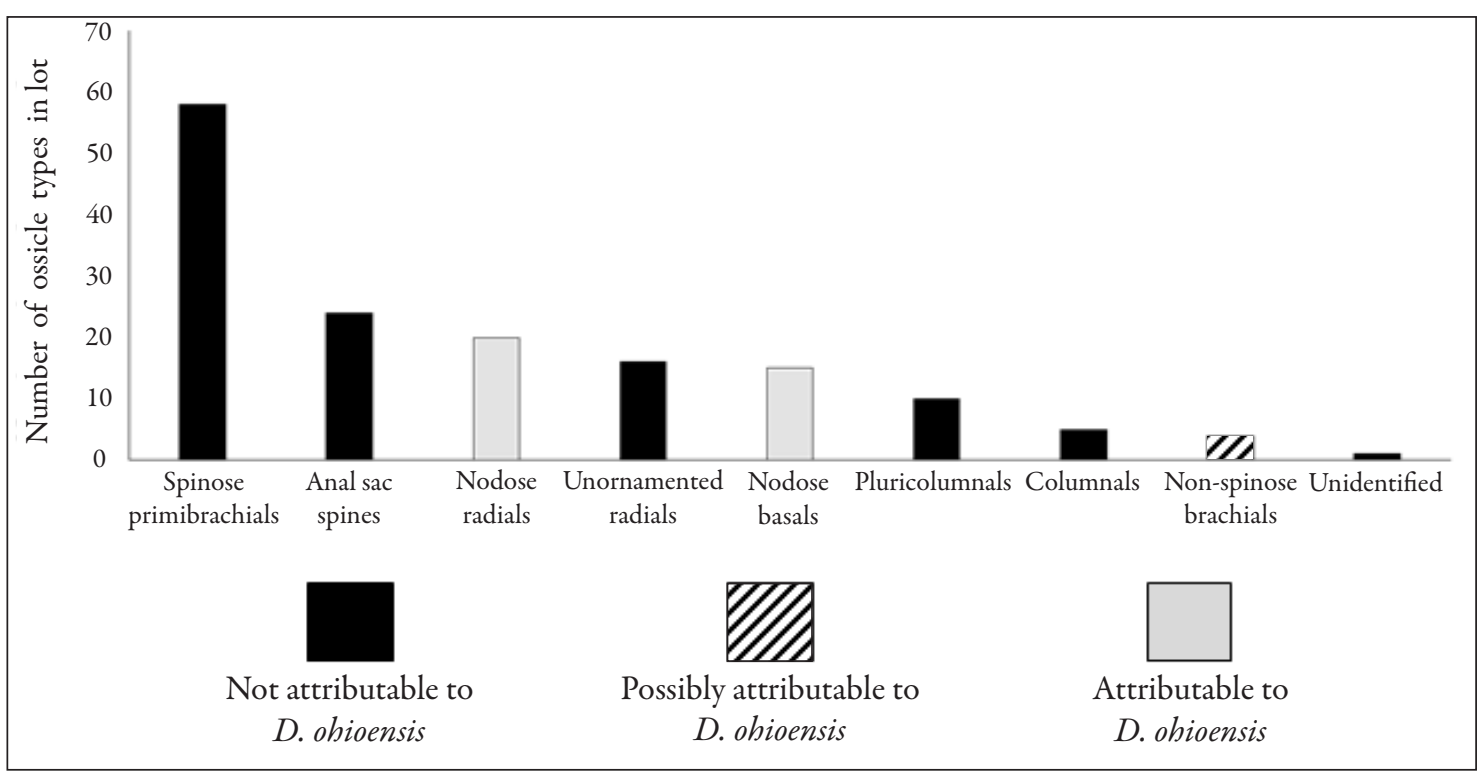

FIGURE 1. Distribution of crinoid ossicle types in CMNH 16597. Of the 153 specimens in this lot, 35 are attributed to Diphuicrinus ohioensis and 4 may potentially belong to that species but cannot be reliably identified because the arms of D. ohioensis remain unknown.

All plates were recovered from the Middle Pennsylvanian Putnam Hill Limestone of the Allegheny Group from an abandoned strip mine north and east of a tributary of Elk Fork, about $3.4 \mathrm{~km}$ northwest of McArthur, Vinton County, southeastern Ohio (lat $39^{\circ} 16^{\prime} 35^{\prime \prime} \mathrm{N}$, long $82^{\circ} 29^{\prime} 40^{\prime \prime} \mathrm{W}$ ). This locality is the same as "Locality 3 " of Burke (1976), a site from which several of the articulated cups that serve as type material for D. ohioensis were collected, namely paratypes USNM (United States National Museum of Natural History) 166575 and USNM 166576. However, the specimen label of $\mathrm{CMNH}$ 16597 states that the assemblage of isolated ossicles was collected by J. J. Burke in 1965, over a decade before publication of the description of $D$. ohioensis. Consequently, these ossicles have long been listed as unidentified and were not included in the formal description of this species (Burke 1976).

\section{RESULTS}

A sample of isolated cup plates in CMNH 16597 closely matches the description for corresponding portions of D. ohioensis given by Burke (1976). The most distinctive features are: (1) the relatively large forefacet (aboral ligament fossa) on radial plates, an inherent feature of diphuicrinids (Strimple and Moore 1971), with a diagnostically shallower forefacet relative to internal facetal areas (Burke 1976); and (2) the prominent sculpture on exteriors of basal (Fig. 2) and radial plates (Fig. 3), which is coarser and characterized by more discrete nodes than in most other crinoids with otherwise similar calyx plating patterns and cup morphologies, such as Graffhamicrinus Strimple, 1961 (Strimple 1977). As indicated in Fig. 1, isolated radial and basal plates are described in this study; although some non-spinose brachials may represent $D$. ohioensis, the arms of this species are currently unknown, so brachials cannot be reliably identified.

Approximately $74.3 \%$ of D. ohioensis ossicles (12 of 15 basal plates, 14 of 20 radial plates) are encrusted by minute, threadlike, calcareous tubes (Fig. 2B-F, Fig. 3B-D). These are superficially similar to those produced by serpulid (polychaete annelid) worms in modern marine environments. However, true serpulid structures are restricted to younger deposits (Vinn and Mutvei 2009; Ippolitov et al. 2014). Crinoid ossicles vary from being relatively densely encrusted-close to $10 \%$ of surface area covered; Fig. 2 F, Fig. 3D-to only having 1 or 2 short fragments preserved (Fig. 2B, Fig. 3B). Plates are most commonly encrusted on the exterior surfaces, which could have occurred either before or after the death of the crinoid; however, a number of specimens also have encrusting tubes on the interior and/or articular surface of plates, which could only have occurred after the death and total disarticulation of the crinoid. Regardless, 2 patterns are worth documentation: first, where the exterior of plates are encrusted, tubes are present primarily in the low areas in between elevated nodes; second, that long, continuous lengths of calcareous tubes are completely absent and, instead, encrusting calcareous tubes are present in the form of short, incomplete portions (Fig. 2, Fig. 3). 


\section{DISCUSSION}

As no isolated ossicles were discussed in the original description of D. ohioensis (Burke 1976), the discovery of a sample of cup plates represents an additional record of a crinoid taxon known only from a limited number of specimens. Appropriate material within CMNH 16597 can be properly identified, and loose basal and radial plates can now be used to supplement articulated cups in future studies concerned with the morphology of diphuicrinid crinoids. Continued attention to isolated ossicles and other forms of fragmentary material is strongly encouraged. Nearly all museums have an abundance
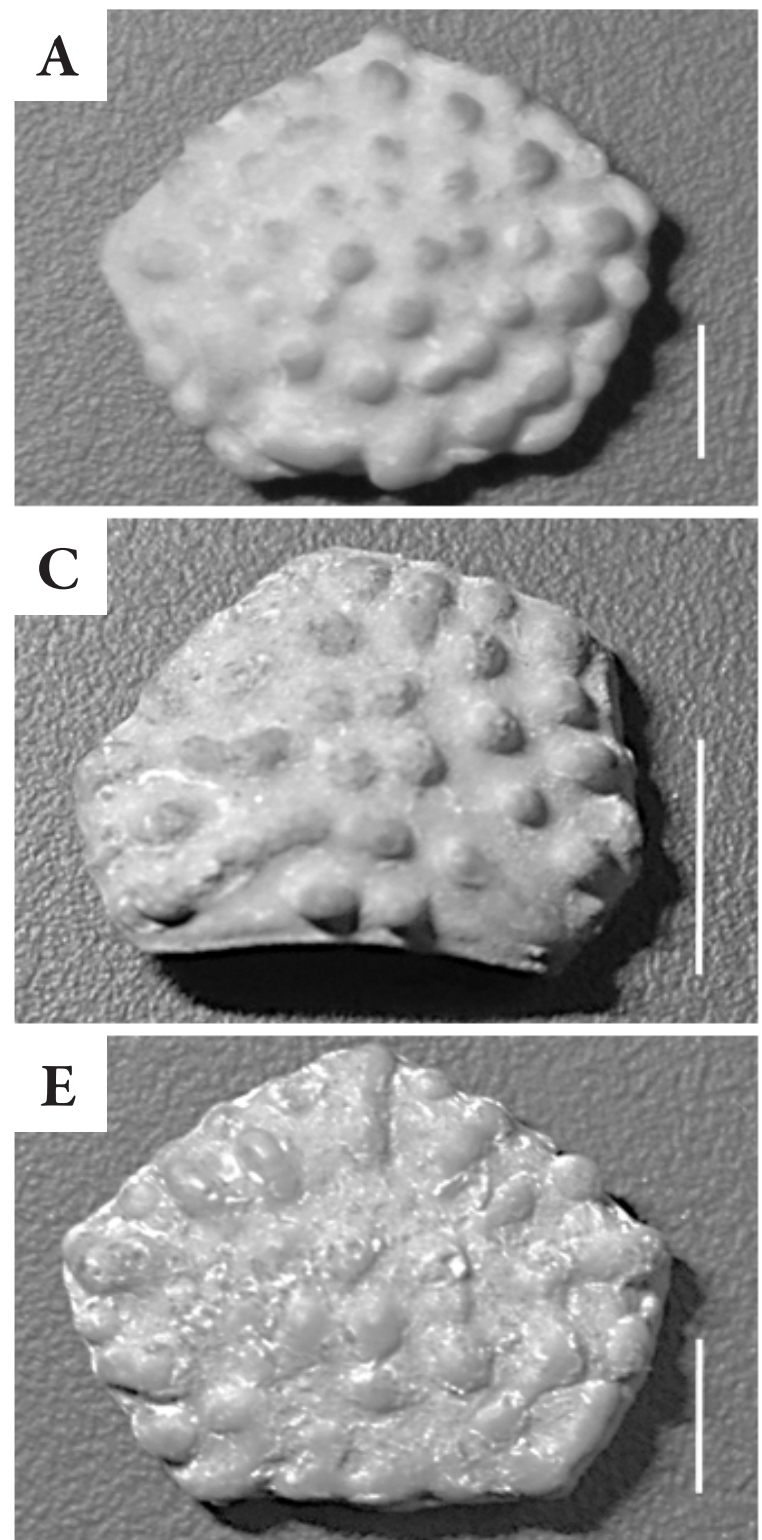

of echinoderm material catalogued as indeterminate loose plates (or the like), and a wealth of information on biodiversity, distribution, and preservation can potentially be gained through scrutiny of specimen lots that are largely overlooked in favor of articulated material.

The high frequency of encrustation of $D$. ohioensis ossicles by small, calcareous tubes was not previously documented in the initial description and interpretation of this taxon. Scanning electron microscopy of these tubes revealed at least 2 recognizable forms (Fig. 4). Most can be identified as microconchids (Fig. 4A-E), which are enigmatic
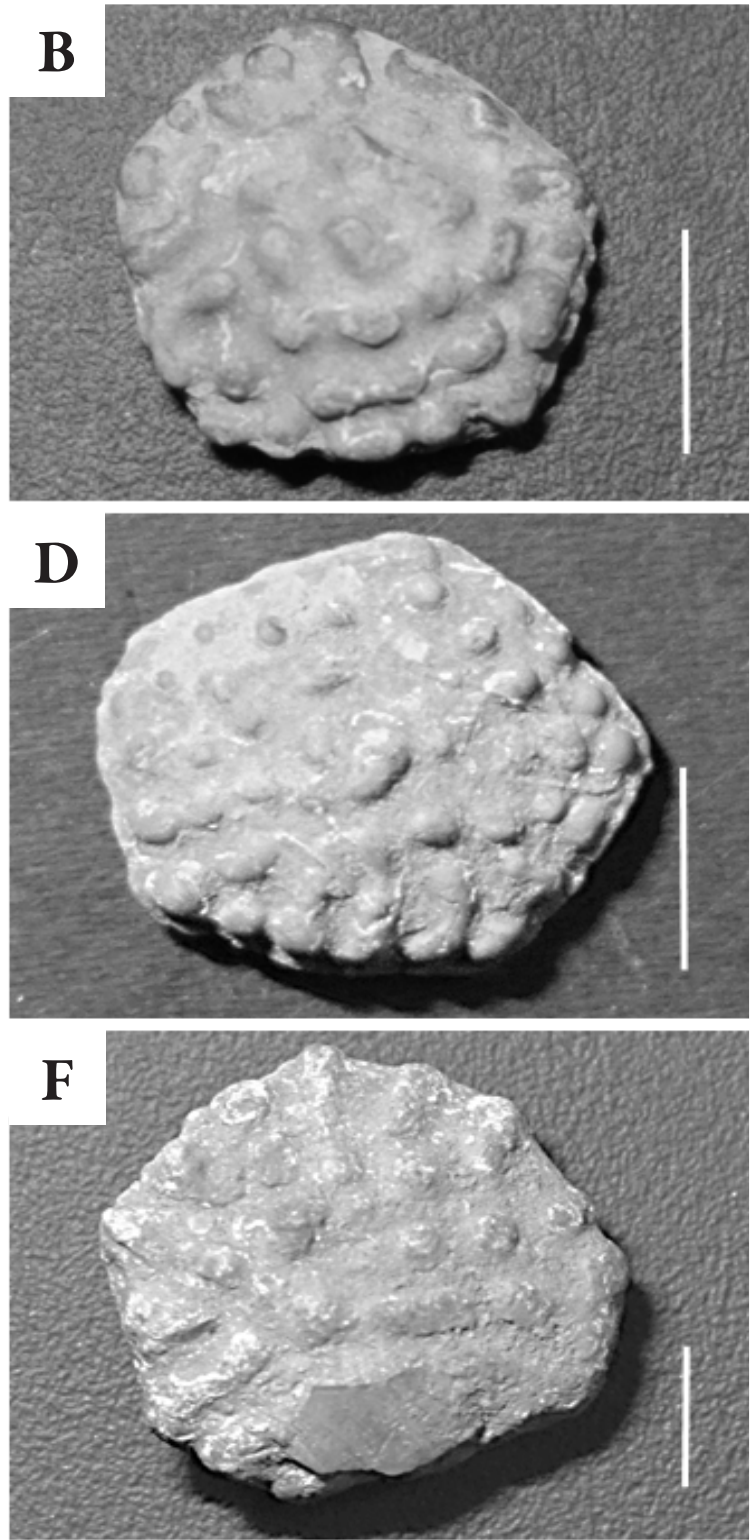

FIGURE 2. Examples of basal plates belonging to Diphuicrinus ohioensis from the Middle Pennsylvanian Putnam Hill Limestone of Vinton County, Ohio (all reposited as CMNH 16597). (A) Well-preserved plate lacking encrustation by calcareous tubes. (B) Sparsely encrusted plate; note the thin, light-colored tubes in low areas between nodes. (C) Fairly sparsely encrusted plate with numerous segments of tubes most commonly located around the base of nodes. (D) Relatively densely encrusted plate with tubes located primarily in the right and bottom half of specimen. (E) Heavily encrusted plate with a large proportion of the exterior surface covered by short, light-colored tube segments. (F) Strongly abraded, heavily encrusted plate with numerous short segments of tubes. All scale bars $=5 \mathrm{~mm}$. 
tentaculitoids that are coiled, at least initially (Zatoń and Vinn 2011; Zatoń et al. 2016; Fig. 4A); a smaller proportion of tubes can be attributed to agglutinated foraminifera (Fig. 4E-F). The microconchids are essentially hollow calcareous tubes showing evidence of accretionary growth (Fig. 4C). The foraminifera are characterized by poorly sorted tests composed of angular sediment grains (Fig. 4F). Although the presence of encrusting organisms offers little in terms of taxonomic information related to crinoids, encrustation represents an important paleoecological and taphonomic phenomenon, and one of the most useful indicators of paleoenvironmental parameters (Brett and Baird 1986; Parsons and Brett 1991). Elevated relative frequencies of encrustation of isolated crinoid ossicles, particularly when encrustation occurs on both the exterior and interior/articular surfaces of cup plates, as in the collection studied here, is a strong indicator of stratigraphic condensation associated with a very low sedimentation rate (Thomka et al. 2012). Although this interval of the Putnam Hill Limestone has yielded articulated cladid crinoid cups, as described by Burke (1976), these reflect relatively rare obrution (rapid burial) events that episodically punctuated an environment with an otherwise minimal sediment influx (e.g., Brett and Baird 1986; Thomka et al. 2012).

The preferential encrustation of smooth, depressed areas in between the elevated nodes on basal and radial plate exteriors is an unusual taphonomic feature. There are 3 potential explanations for this pattern. The first interpretation is that the lower areas offered some advantage in terms of strength and/or persistence of currents. This seems least likely given the tendency of suspension-feeding organisms to more commonly encrust elevated areas over depressed ones (Taylor and Wilson 2003); however, the orientation of isolated plates on the seafloor or the overall microtopographic complexity of the coarsely sculptured plates may have somehow contributed to unusual water flow in the areas between nodes. The second interpretation is that the spaces in between nodes represented broader, flatter areas that were more suitable as sites for encrustation. Although a few portions of calcareous tubes extend from lower areas up onto the bases of nodes, these segments are no more than a few millimeters in length and never wrap around lower portions of nodes, suggesting that such structures might have represented substrata that were not preferred. The third interpretation is that
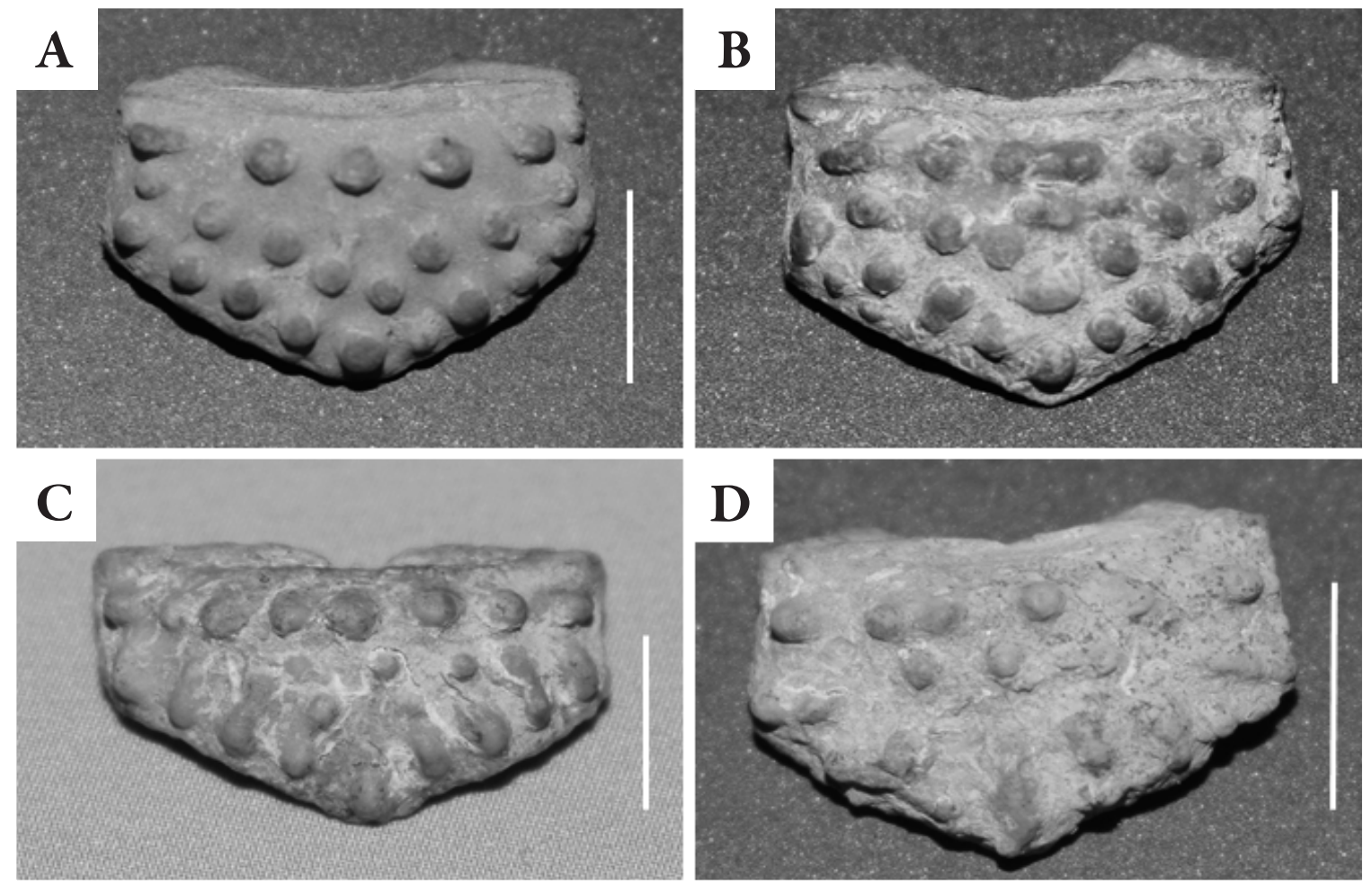

FIGURE 3. Examples of radial plates belonging to Diphuicrinus ohioensis from the Middle Pennsylvanian Putnam Hill Limestone of Vinton County, Ohio (all reposited as CMNH 16597). (A) Well-preserved, clean plate lacking encrusting organisms. (B) Sparsely to moderately encrusted plate with segments of tubes occurring primarily in the right side of the specimen. (C) Moderately encrusted plate with numerous, highly arcuate partial tubes at the base of nodes primarily in the center of the specimen. (D) Poorly preserved, heavily encrusted plate with most of the surface area in between prominent nodes covered in thin, highly incomplete tubes. All scale bars $=5 \mathrm{~mm}$. 

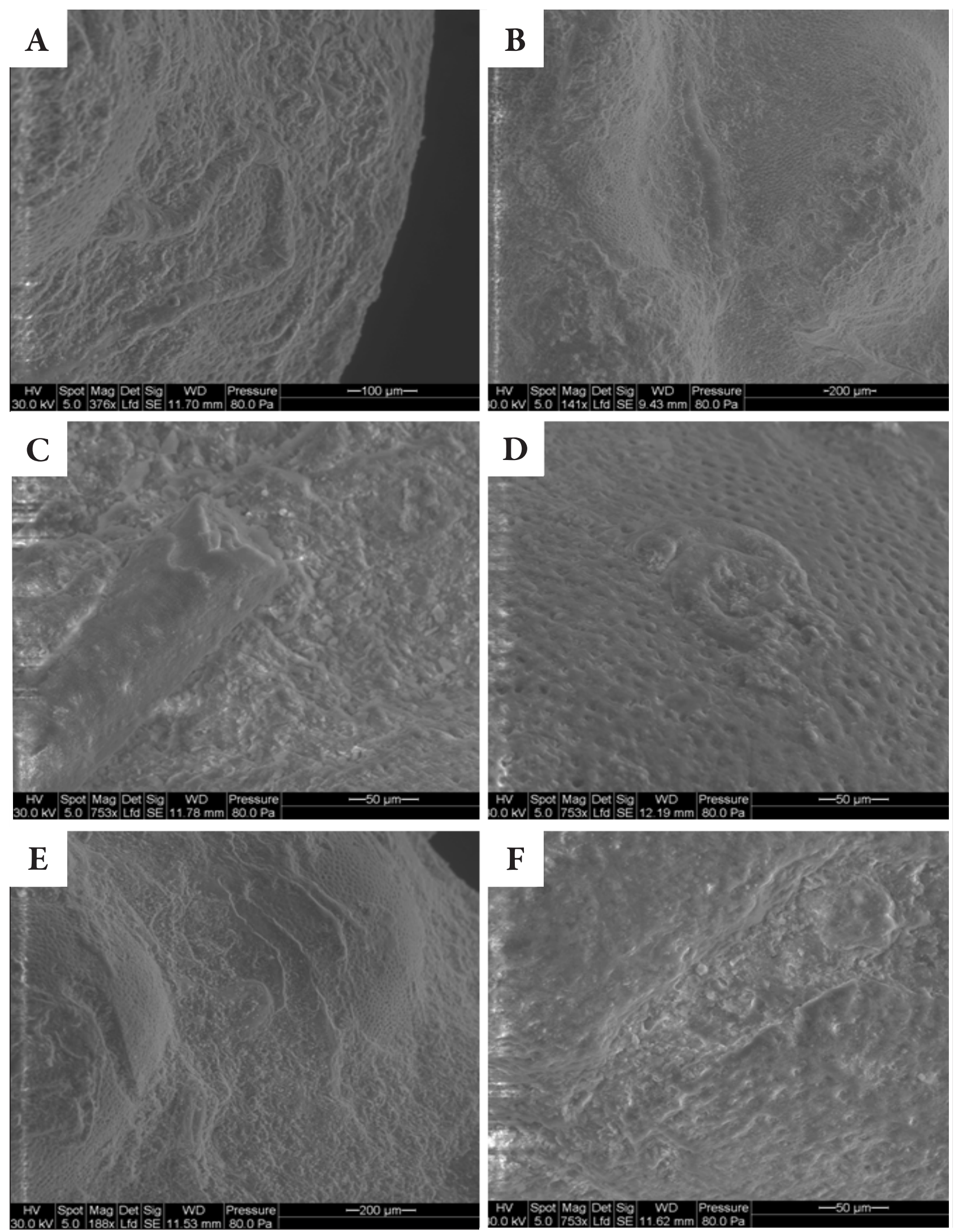

FIGURE 4. Scanning electron microscope images of encrusting vermiform tubes on isolated plates of Diphuicrinus ohioensis. (A) Example of a contorted microconchid tube on a basal plate, with a highly weathered specimen visible on the bottom of the node in the background. (B) Relatively straight microconchid tube in between 2 elevated nodes of a basal plate. (C) Close-up view of the aperture of a microconchid tube on a radial plate. Note that the morphology is a simple, undivided, hollow tube. (D) Larval settlement area for a microconchid showing the diagnostically coiled orientation. (E) Agglutinated foraminiferan encrusting the node in the left foreground, with several heavily weathered microconchid tubes in the center and upper portion of the image. (F) Close-up view of elongate agglutinated foraminiferan test showing the poorly sorted texture. 
encrustation was initially more ubiquitous across the exterior of cup plates, but post-mortem abrasion by currents removed portions of the calcareous tubes that were exposed on elevated nodes. See similar phenomenon described in Donovan (1999) for encrustation of pumice fragments. Given the evidence for slow sedimentation and consequent extended residence time of bioclasts in seafloor sediment prior to burial (see above), prolonged exposure to natural sandblasting by currents may have effectively stripped away encrusters from the nodes, thereby restricting their preservation to the protected internode areas. This may be supported by the incomplete and seemingly fragmented state of encrusting tubes (Fig. 2, Fig. 3, Fig. 4). Similar patterns are likely to be documented if careful attention is paid to the distribution of encrusting organisms on sculptured echinoderm ossicles in future studies. Information derived from such studies has the potential to clarify the precise cause(s) of the patterns described here.

\section{ACKNOWLEDGEMENTS}

Access to material analyzed in this study was generously provided by Joseph T. Hannibal and Douglas Dunn of the Cleveland Museum of Natural History. Assistance with scanning electron microscopy was provided by Thomas J. Quick and Sarah A. Burgess (University of Akron). Previous versions of this article were improved by the constructive comments from Stephen K. Donovan (NCB-Naturalis) and 2 anonymous reviewers.

\section{LITERATURE CITED}

Ausich WI. 1997. Regional encrinites: a vanished lithofacies. In: Brett CE, Baird GC, editors. Paleontological Events: Stratigraphic, Ecological, and Evolutionary Implications. New York: Columbia University Press. p. 509-519.

Brett CE, Baird GC. 1986. Comparative taphonomy: a key to paleoenvironmental interpretation based on fossil preservation. Palaios. 1(3):207-227. https://doi.org/10.2307/3514686

Burke JJ. 1976. A new crinoid from the Putnam Hill Limestone member (Allegheny Group, Pennsylvanian) of Ohio. Kirtlandia. 23:1-10.

Donovan SK. 1986. Pelmatozoan columnals from the Ordovician of the British Isles, part 1. Monogr Palaeontograph Soc. 138:1-68.

Donovan SK. 1999. Pumice and pseudoplankton: geological and paleontological implications of an example from the Caribbean. Caribbean J Sci. 35(3-4):323-324

Fearnhead FE, Donovan SK, Ewin TAM. 2013. Palaeobiology of Floricolumnus (col.) girvanensis Donovan \& Clark (Crinoidea; Silurian) from the Girvan district, Ayrshire. Scott J Geol. 49(1):1-7. https://doi.org/10.1144/sjg2012-447
Holterhoff PF. 1997. Paleocommunity and evolutionary ecology of Paleozoic crinoids. In: Waters JA, Maples CG, editors. Geobiology of Echinoderms. Paleontological Society Papers 3. p. 69-106.

Ippolitov AP, Vinn O, Kupriyanova EK, Jäger M. 2014. Written in stone: history of serpulid polychaetes through time. Mem Mus Victoria. 71:123-159.

https://doi.org/10.24199/j.mmv.2014.71.12

Jeffords RM. 1978. Dissociated crinoid skeletal elements. In: Moore RC, Teichert C, editors. Treatise on Invertebrate Paleontology, Part T, Echinodermata 2. p. 928-937.

Lewis RD. 1980. Taphonomy. In: Waters JA, Broadhead TW, editors. Echinoderms: Notes for a Short Course. University of Tennessee Studies in Geology 3. p. 27-39.

Lowenstam HA. 1957. Niagaran reefs in the Great Lakes area. In: Ladd HS, editor. Treatise on Marine Ecology and Paleoecology. Geological Society of America Memoir 67. p. 215-248.

Moore RC. 1938. The use of fragmentary crinoidal remains in stratigraphic paleontology. Bull Sci Laboratories Denison Univ. 33:165-250.

Moore RC, Jeffords RM. 1968. Classification and nomenclature of fossil crinoids based on studies of dissociated parts of their columns. Univ Kansas Paleontol Cont. 46(Ech. Art. 9):1-86.

Parsons KM, Brett CE. 1991. Taphonomic processes and biases in modern marine environments: an actualistic perspective on fossil preservation. In: Donovan SK, editor. The Processes of Fossilization. New York: Columbia University Press. p. 22-64.

Strimple HL. 1961. Late Desmoinesian crinoid faunule from Oklahoma. Oklahoma Geol Survey Bull. 93:1-189.

Strimple HL. 1977. Notes concerning Delocrinus and Graffhamicrinus (Crinoidea: Inadunata). Proc Iowa Acad Sci. 84(4):157-162.

Strimple HL, Moore RC. 1971. The family Diphuicrinidae. Univ Kansas Paleontol Cont. 56(Pt. 1):2-8.

Taylor PD, Wilson MA. 2003. Palaeoecology and evolution of marine hard substrate communities. Earth Sci Rev. 62(1-2): 1-103. https://doi.org/10.1016/S0012-8252(02)00131-9

Thomka JR, Brett CE. 2017. Insights into the taxonomy and paleoecology of the 'bead bed' crinoid (Echinodermata: Crinoidea) based on new material from the lower Silurian Brassfield Formation of east-central Kentucky. Palaios. 32(12):762-768. https://doi.org/10.2110/palo.2017.061

Thomka JR, Mosher D, Lewis RD, Pabian RK. 2012. The utility of isolated crinoid ossicles and fragmentary crinoid remains in taphonomic and paleoenvironmental analysis: an example from the Upper Pennsylvanian of Oklahoma, United States. Palaios. 27(7):465-480. https://doi.org/10.2110/palo.2011.p11-125r

Vinn O, Mutvei H. 2009. Calcareous tubeworms of the Phanerozoic. Estonian J Earth Sci. 58(4):286-296. https://doi.org/10.3176/earth.2009.4.07

Zatoń M, Vinn O. 2011. Microconchids and the rise of modern encrusting communities. Lethaia. 44(1):5-7. https://doi.org/10.1111/j.1502-3931.2010.00258.x

Zatoń M, Vinn O, Toom U. 2016. A new microconchid species from the Silurian of Baltica. Estonian J Earth Sci. 65(2): 115-123. https://doi.org/10.3176/earth.2016.09 